\title{
Reactive sputtering of delta-ZrH2 thin films by high power impulse magnetron sputtering and direct current magnetron sputtering
}

\author{
Hans Högberg, Lina Tengdelius, Mattias Samuelsson, Fredrik Eriksson, Esteban Broitman, \\ Jun $\mathrm{Lu}$, Jens Jensen and Lars Hultman
}

\section{Linköping University Post Print}

\section{Tweet}

N.B.: When citing this work, cite the original article.

Original Publication:

Hans Högberg, Lina Tengdelius, Mattias Samuelsson, Fredrik Eriksson, Esteban Broitman, Jun Lu, Jens Jensen and Lars Hultman, Reactive sputtering of delta-ZrH2 thin films by high power impulse magnetron sputtering and direct current magnetron sputtering, 2014, Journal of Vacuum Science \& Technology. A. Vacuum, Surfaces, and Films, (32), 4, 041510.

http://dx.doi.org/10.1116/1.4882859

Copyright: American Vacuum Society http://www.avs.org/

Postprint available at: Linköping University Electronic Press

http://urn.kb.se/resolve?urn=urn:nbn:se:liu:diva-109234 


\title{
Reactive sputtering of $\delta-\mathrm{ZrH}_{2}$ thin films by high power impulse magnetron sputtering and direct current magnetron sputtering
}

\author{
Hans Högberga and Lina Tengdelius, \\ Department of Physics, Chemistry, and Biology (IFM) Linköping University, SE-581 83 \\ Linköping, Sweden.
}

Mattias Samuelsson

Impact Coatings AB, Westmansgatan 29, SE-582 16 Linköping, Sweden

Fredrik Eriksson, Esteban Broitman ${ }^{\text {a)}, ~ J u n ~ L u, ~ J e n s ~ J e n s e n, ~ a n d ~ L a r s ~ H u l t m a n ~}$

Department of Physics, Chemistry, and Biology (IFM) Linköping University, SE-581 83 Linköping, Sweden.

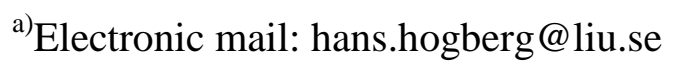

Reactive sputtering by high power impulse magnetron sputtering (HiPIMS) and direct current magnetron sputtering (DCMS) of a $\mathrm{Zr}$ target in $\mathrm{Ar} / \mathrm{H}_{2}$ plasmas was employed to deposit $\mathrm{Zr}-\mathrm{H}$ films on $\mathrm{Si}(100)$ substrates, and with $\mathrm{H}$ content up to 61 at.\% and $\mathrm{O}$ contents typically below 0.2 at.\% as determined by elastic recoil detection analysis. X-ray photoelectron spectroscopy reveals a chemical shift of $\sim 0.7 \mathrm{eV}$ to higher binding energies for the $\mathrm{Zr}-\mathrm{H}$ films compared to pure $\mathrm{Zr}$ films consistent with a charge transfer from $\mathrm{Zr}$ to $\mathrm{H}$ in a zirconium hydride. $\mathrm{X}$-ray diffraction shows that the films are single-phase $\delta-\mathrm{ZrH}_{2}\left(\mathrm{CaF}_{2}\right.$-type structure $)$ at $\mathrm{H}$ content $>$ $\sim 55$ at.\% and pole figure measurements give a 111 preferred orientation for these films. Scanning electron microscopy cross-section images show a glasslike microstructure for the HiPIMS films, while the DCMS films are columnar. Nanoindentation yield hardness values of 5.5-7 GPa for the $\delta-\mathrm{ZrH}_{2}$ films that is slightly harder than the $\sim 5 \mathrm{GPa}$ determined for $\mathrm{Zr}$ films and with coefficients of friction in the range $0.12-0.18$ to compare with the $0.4-0.6$ obtained 
for $\mathrm{Zr}$ films. Wear resistance testing show that phase-pure $\delta-\mathrm{ZrH}_{2}$ films deposited by HiPIMS exhibit up to 50 times lower wear rate compared to those containing a secondary $\mathrm{Zr}$ phase. Four-point probe measurements give resistivity values in the range of $\sim 100-120 \mu \Omega \mathrm{cm}$ for the $\delta-\mathrm{ZrH}_{2}$ films, which is slightly higher compared to $\mathrm{Zr}$ films with values in the range $70-80$ $\mu \Omega \mathrm{cm}$.

\section{INTRODUCTION}

The early transition metal zirconium exhibits a high affinity to hydrogen, which results in the formation of hydrides. The $\mathrm{Zr}-\mathrm{H}$ phase diagram ${ }^{1,2}$ reveals at least two phases that are stable above room temperature, possibly up to $900{ }^{\circ} \mathrm{C} .{ }^{1}$ These are $\delta-\mathrm{ZrH}_{2}\left(\mathrm{CaF}_{2}\right.$-type structure) and $\varepsilon-\mathrm{ZrH}_{2}$ (body-centered tetragonal with $\mathrm{ThH}_{2}$-type structure), where $\delta-\mathrm{ZrH}_{2}$ exhibits a lattice constant of $\mathrm{a}=4.781 \AA{ }^{3}$ and $\varepsilon-\mathrm{ZrH}_{2}$ shows the lattice constants, $\mathrm{a}=3.5199 \AA$ and $\mathrm{c}=4.4500$ $\AA$, ${ }^{4}$. In addition to $\delta-\mathrm{ZrH}_{2}$ and $\varepsilon-\mathrm{ZrH}_{2}$, there are metastable phases with a face-centered tetragonal phase $\gamma-\mathrm{ZrH}$ and an ordered structure with the composition $\mathrm{Zr}_{2} \mathrm{H}$ that is fully coherent with $\alpha-Z r^{5}$ The cubic $\delta$-phase is characterized by a homogeneity range with possible compositions from $\mathrm{ZrH}_{2}$ to approximately $\mathrm{ZrH}_{1.6},{ }^{5}$ while $\varepsilon-\mathrm{ZrH}_{2}$ is reported to exhibit a somewhat smaller homogeneity range with compositions between $\mathrm{ZrH}_{2}$ to $\mathrm{ZrH}_{1.7}{ }^{1}$ Using firstprinciple calculations of the electronic structures for $\delta-\mathrm{ZrH}_{2}$ and $\varepsilon-\mathrm{ZrH}_{2}$, the electrical and mechanical properties have been assessed ${ }^{6-9}$. The calculated density of state at the Fermi level reported in these studies support experimental results on good electrical conductivity for both phases and the calculations show that the d-bands of zirconium play a dominant role in the electrical transport. The chemical bonding in $\delta-\mathrm{ZrH}_{2}$ and $\varepsilon-\mathrm{ZrH}_{2}$ is characterized by strong interaction between zirconium and hydrogen, and in the works by Zhang et al. ${ }^{8}$ and Chihi et $a l .{ }^{9}$ it is concluded that the $\mathrm{Zr}-\mathrm{H}$ bonding exhibits higher degree of ionic character than covalent type of bonding. A less directional bond is also to be expected in zirconium hydrides compared to for instance $\mathrm{ZrC}$ and $\mathrm{ZrN}$, since the interaction occurs between $\mathrm{Zr}$ d-orbitals and 
$\mathrm{H}$ s-orbital in the hydride, while the high hardness values and extreme melting points found for carbides and nitrides stem from the interaction between the metal d-orbitals and the highly directional p-orbitals of carbon or nitrogen. As a consequence, $\delta-\mathrm{ZrH}_{2}$ and $\varepsilon-\mathrm{ZrH}_{2}$ demonstrate lower hardness values and melting points compared to $\mathrm{ZrC}$ and $\mathrm{ZrN}$.

Experimentally, the properties of these $\mathrm{ZrH}_{2}$ phases have been verified in bulk material, using pieces of zirconium metal that have been heat treated in a $\mathrm{H}_{2}$ atmosphere for 1 to 2 days and at elevated temperatures up to $900{ }^{\circ} \mathrm{C} .{ }^{10,11}$ Of particular interest to the present study are reports on the chemical bonding structure, ${ }^{10,12}$ structural properties, ${ }^{12}$ electrical properties, ${ }^{11,12}$ and mechanical properties. ${ }^{13,14}$ The literature show that $\delta-\mathrm{ZrH}_{2}$ and $\varepsilon-\mathrm{ZrH}_{2}$ are good conductors that demonstrate slightly higher hardness value than the metal, and that the properties are determined by both the phase composition and the stoichiometry (hydrogen content) of the material. Specifically, lower nanoindentation hardness value for $\delta-\mathrm{ZrH}_{2-\mathrm{x}}$ of $\sim 4.5 \mathrm{GPa}$ has been reported in (Ref.10), whereas the data on the melting points of $\delta-\mathrm{ZrH}_{2}$ and $\varepsilon-\mathrm{ZrH}_{2}$ are rather uncertain according to the available phase diagrams, ${ }^{1,2}$ but considerably lower compared to $\mathrm{ZrC}$ and $\mathrm{ZrN}$.

However, the $\mathrm{Zr}-\mathrm{H}$ phase diagram has been, and still is, the subject of discussions and investigations given uncertainties both with respect to, e.g., the number of existing phases, their homogeneity ranges, and melting points. Nevertheless, the reports presented above clearly demonstrate that zirconium hydrides are materials with unique properties. Also, it is well known that the properties of a material in thin film form may differ from those that the same material exhibits in bulk form.

In comparison to borides, carbides, nitrides, and oxides, hydride thin films are scarcely studied, which is particularly evident for zirconium hydrides. The aim of the present study is to demonstrate the synthesis of $\mathrm{ZrH}_{2}$ in thin film form, and study the influence of growth 
process parameters, as well as compare the materials properties in thin film form with that of the bulk material. Magnetron sputtering is a commonly used thin film growth technique that operates at non-equilibrium conditions. ${ }^{15}$ Therefore thin film techniques such as magnetron sputtering constitute suitable synthesis routes for these materials and enable growth of materials with well-defined properties. This will be favorable for in-depth property characterization of these materials and provide a possible route in the search for metastable phases, as has previously been shown for other ceramics, e.g. TiAlN. ${ }^{16}$

We have studied reactively sputtered zirconium hydride thin films, synthesized using high power impulse magnetron sputtering (HiPIMS) and direct current magnetron sputtering (DCMS), and investigated their properties with respect to their chemical bonding structure, composition, and structural properties including the growth relationship to the substrate material, microstructure, as well as their mechanical and electrical properties. The growth was carried out in an industrial scale deposition system without external heating to avoid decomposition of phases potentially stable at low-temperatures. To minimize the influence of the residual gas on the film properties, short deposition times and high power densities on the target were used.

\section{EXPERIMENTAL PROCEDURES}

The depositions were carried out at a fixed target to substrate distance of $7 \mathrm{~cm}$ and using no external substrate heating in a commercial industrial high vacuum (HV) coating system $\left(\mathrm{CemeCon} \mathrm{CC} 800 / 9^{\circledR}\right.$ ) that had been evacuated to a base pressure below $2.2 \times 10^{-4} \mathrm{~Pa}$ prior to growth. Getter pumping was applied immediately before deposition to further minimize the impact of residual gas, using sputtering of a rectangular shaped titanium target $(50 \times 8.8 \mathrm{~cm})$ at a power of $1500 \mathrm{~W}$ onto the backside of a shutter that covered the magnetron during $600 \mathrm{~s}$ and at a pressure of $0.42 \mathrm{~Pa}$. The films were reactively sputtered onto $\mathrm{Si}(100)$ substrates, 2 in 
each run, at a substrate bias of $-80 \mathrm{~V}$ by DCMS or HiPIMS from a zirconium target with a purity higher than $99.9 \%$ ( $\mathrm{Hf} 0.05 \%)$ in $\mathrm{Ar}(99.9997 \%) / \mathrm{H}_{2}(99.9996 \%)$ plasmas containing $0 \%, 2.5 \%, 5 \%, 10 \%, 15 \%$, and $20 \% \mathrm{H}_{2}$, as determined from the resulting total pressure at the beginning of the deposition cycle. The Ar partial pressure was fixed at $0.42 \mathrm{~Pa}$ and as no pressure control was applied for the reactive gas the pressure increased during the process, which was particularly evident for the HiPIMS processes performed with high hydrogen content in the plasma. The sputtering power, after ramping of the power behind a shutter, was $5000 \mathrm{~W}$ for growth of the DCMS films, which corresponds to $11.36 \mathrm{~W} / \mathrm{cm}^{2}$ on the $50 \mathrm{x} 8.8$ cm target. The HiPIMS films were deposited at an average constant power of $3000 \mathrm{~W}$ (6.82 $\mathrm{W} / \mathrm{cm}^{2}$ on the $50 \times 8.8 \mathrm{~cm}$ target), using a pulse width of $150 \mu$ s and with a pulse repetition frequency of $300 \mathrm{~Hz}$. The deposition time was set to $120 \mathrm{~s}$ for the DCMS processes and $496 \mathrm{~s}$ for the HiPIMS processes. The corresponding growth rates were $\sim 70 \AA$ /s for DCMS and $\sim 11$ $\AA /$ s for HiPIMS at the highest hydrogen content in the plasma.

The chemical bonding structure of the as-deposited films was determined by X-ray photoelectron spectroscopy (XPS), using an AXIS Ultra ${ }^{\text {DLD }}$ instrument from Kratos Analytical and analysis with monochromatic $\mathrm{Al} \mathrm{K} \alpha$ radiation. The binding energy (BE) scale was calibrated by setting the position of the Fermi edge of a sputter-cleaned Ag sample to $0.0 \mathrm{eV} .{ }^{17}$ To remove surface oxides and adventitious carbon the samples were sputter etched at an angle of $20^{\circ}$ for $90 \mathrm{~s}$ by $4 \mathrm{kV}$ Ar-ions. The composition and level of impurities in the deposited $\mathrm{Zr}-\mathrm{H}$ films were determined by time-of-flight energy elastic recoil detection analysis (ToF-E ERDA), using energetic, $36 \mathrm{MeV},{ }^{127} \mathrm{I}^{8+}$ ions with a beam incidence angle of $67.5^{\circ}$ to the sample surface normal and a recoil angle of $45^{\circ} .{ }^{18,19}$ The structural properties of the films were assessed by X-ray diffraction (XRD) with a Philips PW 1820 diffractometer operated in Bragg-Brentano geometry and using $\mathrm{Cu} \mathrm{K} \alpha$ radiation at $40 \mathrm{kV}$ and $40 \mathrm{~mA}$. To determine the preferred orientation of the films, pole figure measurements of the 220 and 420 
poles were conducted with a PANalytical EMPYREAN diffractometer operated at $45 \mathrm{kV}$ and $40 \mathrm{~mA}$. The same instrument was used for X-ray reflectivity (XRR) measurements to obtain film densities by fitting the critical angle of total external reflection using the X'Pert Reflectivity software from PANalytical. High-resolution electron microscopy (HREM) crosssectional specimens were manufactured following the conventional routine and with final Arion milling to electron transparency. Both HREM imaging and collection of selected area electron diffraction (SAED) patterns were carried out by using a FEI Tecnai G2 TF20 UT HRTEM instrument with a field emission gun operated at $200 \mathrm{kV}$ and with a point to point resolution of $1.9 \AA$ A. The film microstructure and thickness were determined by cross-sectional scanning electron microscopy (SEM) LEO 1550 Gemini with images recorded at an acceleration voltage of $10 \mathrm{kV}$. The mechanical and tribological properties: hardness, reduced Young's modulus $\left(\mathrm{E}_{\mathrm{r}}\right)$, friction, and wear rate were investigated, using a Hysitron Triboindenter TI950 instrument. The hardness was measured by indentation from a Berkovich diamond probe at an applied load of $500 \mu \mathrm{N}$, and $\mathrm{E}_{\mathrm{r}}$ was calculated from these values. In all the indentation experiments, the penetration depth of the indenter was lower than $10 \%$ of the film thickness to avoid the influence of the substrate. The friction coefficient $(\mu)$ was determined by a 40 cycles reciprocal test of $10 \mu \mathrm{m}$ length with a diamond conical probe ( 5 $\mu \mathrm{m}$ diameter) at a load of $50 \mu \mathrm{N}$. Nanowear tests were conducted by raster scanning the indenter with a $90^{\circ}$ cube corner tip across the sample surface while maintaining a normal force $\mathrm{W}$ of $100 \mu \mathrm{N}$. The root mean squared (RMS) film roughness was determined, using the tip in Scanning Probe Mode (SPM) at a load of $3 \mu \mathrm{N}$ on a square area of $10 \times 10 \mu \mathrm{m}^{2}$. A square area of $5 \times 5 \mu \mathrm{m}^{2}$ was selected for five times scans at the higher load, and then the tip was used in SPM at a load of $3 \mu \mathrm{N}$ to acquire topographical information of the worn region of the film. The wear scar volume was obtained by the measurement of average height $\mathrm{h}$ of the worn surface and the wear rate $\mathrm{k}$ was calculated by equation $\mathrm{k}=\mathrm{h} / \mathrm{nW}$, where $\mathrm{n}$ is the number 
of scanning passes. ${ }^{20}$ Finally, the electrical resistivity values of the films were calculated from measured sheet resistivity data as determined from four point probe measurements with Model 280C (Four Dimensions) instrument and using the film thicknesses determined from SEM images.

\section{RESULTS AND DISCUSSION}

\section{A. Chemical bonding structure and elemental composition}

The high resolution XPS spectra in Fig. 1 were obtained from the $\mathrm{Zr} 3 \mathrm{~d}$ photoelectron region of a $\mathrm{Zr}-\mathrm{H}$ film deposited by HiPIMS with $20 \% \mathrm{H}_{2}$ in the plasma (solid line) and from a $\mathrm{Zr}$ reference film grown by HiPIMS (dashed line). As can be seen, there is a chemical shift towards higher binding energies for the film grown with hydrogen in the plasma compared to the pure metal film. This shift of $\sim 0.7 \mathrm{eV}$ determined from the positions of $\mathrm{Zr} 3 \mathrm{~d}_{5 / 2}$ peaks originates from a charge transfer from $\mathrm{Zr}$ atoms to $\mathrm{H}$ atoms, which is a consequence of the higher electronegativity $(\chi)$ of $\mathrm{H}$ compared to $\mathrm{Zr}$ with $\chi=2.2$ for hydrogen and $\chi=1.33$ for zirconium. $^{21}$ Here, we note that no chemical shifts were evident in the XPS analysis conducted on films where the group 5 metal Ta $(\chi=1.50)$ and the group 6 metal $\mathrm{Cr}(\chi=1.66)$ were reactively sputtered in $\mathrm{H}_{2}$ containing plasmas by HiPIMS and DCMS. ${ }^{22}$ Furthermore, the peak positions for the $\mathrm{Zr}-\mathrm{H}$ film in Fig. 1 was determined to $\mathrm{Zr} 3 \mathrm{~d}_{5 / 2}=179.44 \mathrm{eV}$ and $\mathrm{Zr}$ $3 \mathrm{~d}_{3 / 2}=181.85 \mathrm{eV}$, where the position of the former peak is in good agreement with the binding energies of $179.375 \mathrm{eV}$ reported for a bulk $\delta-\mathrm{ZrH}_{1.74}$ material ${ }^{12}$ and $179 \mathrm{eV}$ determined for a bulk $\mathrm{ZrH}_{1.9}$ material. ${ }^{10}$ For the reference film in Fig. 1, the peaks were located at $\mathrm{Zr} 3 \mathrm{~d}_{5 / 2}=178.75 \mathrm{eV}$ and $\mathrm{Zr} 3 \mathrm{~d}_{3 / 2}=181.15 \mathrm{eV}$, which is in excellent agreement with the work by Nyholm and Mårtensson. ${ }^{23}$

As XPS is unable to detect hydrogen, ToF-E ERDA was used for qualitative and quantitative analysis of the films constituents as well as the contaminants present in the films. Table I 
shows that the hydrogen content in the HiPIMS and DCMS deposited films scales with the amount of $\mathrm{H}_{2}$ in the plasma as exemplified by the fact that HiPIMS films exhibit 55 at.\% $\mathrm{H}$ when growth is conducted with $5 \% \mathrm{H}_{2}$ in the plasma, 59.1 at. $\%$ with $10 \% \mathrm{H}_{2}$ in the plasma, and finally 61.1 at. $\% \mathrm{H}$ with $20 \% \mathrm{H}_{2}$ in the plasma. For the DCMS films, the amount of hydrogen incorporated is less compared to HIPIMS films deposited with the same hydrogen content in the plasma seen from the results with 22.9 at. $\%$ with $10 \% \mathrm{H}_{2}$ in the plasma, and 53.6 at. $\% \mathrm{H}$ with $20 \% \mathrm{H}_{2}$ in the plasma. The higher hydrogen content in the HiPIMS films is likely due to the higher plasma density characteristic for the technique to yield a more efficient dissociation of the $\mathrm{H}_{2}$ molecule as well as by the lower growth rate that will allow more hydrogen to react with the sputtered metal to form a hydride - particularly as no external heating was applied in our study. For the latter, we find support from the synthesis of bulk $\delta-\mathrm{ZrH}_{2}$ and $\varepsilon-\mathrm{ZrH}_{2}$ samples, where 1-2 days of $\mathrm{H}_{2}$ treatment at elevated temperatures is typically applied. ${ }^{10,11}$ Furthermore, we investigated the long-term stability of the films by analyzing one HiPIMS film and one DCMS film deposited with $20 \% \mathrm{H}_{2}$ in plasma at two separate occasions following close to 5 months of storage. As can be seen, Table I shows slightly lower hydrogen content in both films following storage. However, the small difference of $\sim 2$ to 3 at. $\%$ in measured value suggests that the deposited $\mathrm{ZrH}_{2}$ films are stable over time.

In addition, Table I shows that the level of $\mathrm{O}, \mathrm{C}, \mathrm{Ar}$, and $\mathrm{N}$ in the films is low. For example, the $\mathrm{O}$ content was typically $<0.1-0.3$ at.\% with an exception for a DCMS film deposited with $10 \% \mathrm{H}_{2}$ in the plasma that shows a slightly higher content of 0.7 at. $\%$. The $\mathrm{C}$ content is even lower in the region 0.1 at.\%, albeit with slightly higher Ar content of $<0.4$ at.\% in the HiPIMS films, which is probably explained by Ar implantation given the intense ionbombardment often present when using this technique. ${ }^{24}$ The $\mathrm{N}$ content was also very low with about 0.1 at.\% of $\mathrm{N}$ in the analyzed films. The low level of contaminants encountered in 
the $\mathrm{Zr}-\mathrm{H}$ films is in agreement with results in (Ref. 22), where $\beta$-Ta and $\mathrm{Cr}$ films were sputtered by HiPIMS and DCMS in $\mathrm{H}_{2}$ containing plasmas and under HV conditions. Thus, this study support the suggestion made by Högberg et al. ${ }^{22}$ that $\mathrm{H}_{2}$ chemically interacts with species from the residual gas present on the film surface during growth to decrease the level of contaminants in the deposited films.

\section{B. Structural properties}

The XRD patterns in Fig. 2 were recorded from films deposited by HiPIMS to the left and DCMS to the right with $\mathrm{Zr}$ reference films found in the bottom of each respective stack and then followed by films deposited with increasing hydrogen content in the plasma and finally ending with films deposited with $20 \% \mathrm{H}_{2}$ in the plasma. In both diffractograms, the reference films display three peaks originating from $\mathrm{Zr}$ with: $10 \overline{1} 0$ at $2 \theta \approx 32^{\circ}, 0002$ at $2 \theta \approx 32.8^{\circ}$, and $10 \overline{1} 1$ at $2 \theta \approx 36.5^{\circ}$ and where the needle-shaped peak at $2 \theta \approx 33.4^{\circ}$ is the forbidden 200 peak from the single crystal substrate. When $\mathrm{H}_{2}$ is added to the plasma the intensities of the $\mathrm{Zr}$ peaks are gradually reduced and finally they are replaced by one single peak positioned at a diffraction angle of $2 \theta \approx 32.4^{\circ}$. This remaining peak can be assigned to the phase $\delta-\mathrm{ZrH}_{2}$ and represents diffraction from the 111 planes. ${ }^{3}$ This demonstrates that a hydride phase has been successfully deposited using both HiPIMS and DCMS. Simulations of XRR measurements conducted on films grown by both techniques, and with $20 \% \mathrm{H}_{2}$ in the plasma, yield densities of $5.96 \mathrm{~g} / \mathrm{cm}^{3}$ for the film deposited with HiPIMS, and $5.91 \mathrm{~g} / \mathrm{cm}^{3}$ for the film were DCMS was applied. Both values are close to the value $5.667 \mathrm{~g} / \mathrm{cm}^{3}$ reported for bulk $\delta-\mathrm{ZrH}_{2}{ }^{3}$ Further support for the growth of $\delta-\mathrm{ZrH}_{2}$ films is provided from the XRD diffractogram shown as inset in Fig. 2 that only show 111, 222, and 333 peaks originating from the phase $\delta-\mathrm{ZrH}_{2}$ together with the Si 400 and 600 peaks. This result suggests that $\delta-\mathrm{ZrH}_{2}$ is preferred compared to $\varepsilon-$ $\mathrm{ZrH}_{2}$ in reactive sputtering of films on $\mathrm{Si}(100)$ substrates by HiPIMS and DCMS. The reason 
for this is probably the larger homogeneity range shown by $\delta-\mathrm{ZrH}_{2}$ compared to $\varepsilon-\mathrm{ZrH}_{2}$ that allows a higher degree of freedom with respect to the hydrogen content in the films. In addition, the diffractograms in Fig. 2 show traces of peaks originating from metallic $\mathrm{Zr}$ in the DCMS films deposited with $15 \% \mathrm{H}_{2}$ in the plasma, while no such peaks are present in the HiPIMS films grown with $15 \% \mathrm{H}_{2}$ in the plasma. This suggests a less efficient incorporation of hydrogen in the DCMS films, which is supported by ToF-E ERDA measurements yielding a hydrogen content of 22.9 at. $\%$ for DCMS film deposited with $10 \% \mathrm{H}_{2}$ in the plasma. A film with such hydrogen content would in the phase diagram ${ }^{1}$ be positioned in the metal-rich two phase region where $\delta-\mathrm{ZrH}_{2}$ and $\mathrm{Zr}$ co-exist, but where possible growth of $\mathrm{Zr}_{2} \mathrm{H}^{4}$, cannot be ruled out. The most probable explanation for this difference is the higher deposition rate and shorter deposition cycle applied in DCMS compared to HiPIMS. Furthermore, when entering the single-phase region of $\delta-\mathrm{ZrH}_{2}$ there is an increasing shift to lower diffraction angles for the $\delta-\mathrm{ZrH}_{2} 111$ peaks for the HiPIMS films. This is likely an effect from compressive stresses induced by the intense ion bombardment during growth by the technique, ${ }^{24}$ as the hydrogen content determined ToF-E ERDA remains more or less constant above for films deposited with more than $5 \% \mathrm{H}_{2}$ in the plasma, see Table I.

As only 111 type of peaks are visible in the XRD patterns from $\delta-\mathrm{ZrH}_{2}$ films this suggests oriented growth to the $\mathrm{Si}(100)$ substrate for the film. XRD pole figure measurements of the 220 pole in Fig. 3a) show a broad ring of high intensity at $\psi \approx 35^{\circ}$ for a film deposited with HiPIMS and $15 \% \mathrm{H}_{2}$ in the plasma. The measured angle corresponds to the angle between the 110 and 111 planes in a cubic structure, while only parts of the ring expected at $\psi \approx 90^{\circ}$ is visible. This is probably due to limitations of the diffractometer at such high tilt angles. The ring shows that the $\delta-\mathrm{ZrH}_{2}$ film is textured and the rotational symmetry of the ring suggests a fiber-textured growth to the $\mathrm{Si}(100)$ substrate. An epitaxial growth behavior is not to be expected in this study as the depositions were carried out without external heating and using 
$\mathrm{Si}(100)$ substrates with the native oxide still present. The preferred orientation is supported by complementary measurements of the 420 pole in b) displaying rings at $\psi \approx 39^{\circ}$ and $\psi \approx 75^{\circ}$ that are close to the angles between 210 and 111 planes.

\section{Microstructure}

The low-resolution micrographs in Fig. 4 are obtained from a HiPIMS film (a) and DCMS film (b) that are deposited with $20 \% \mathrm{H}_{2}$ in the plasma for both films. The images show that both techniques yield $\mathrm{ZrH}_{2}$ films with a smooth surface structure. The film grown by DCMS displays a more pronounced columnar growth behavior compared to the more glasslike microstructure of the film deposited by HiPIMS. High-resolution images obtained from the interface region reveal a sharp interface and good adhesion between the film and the native oxide still present on the substrate (not shown). The surface structure and film microstructure determined are supported by SEM images from the films deposited at the most hydrogen-rich composition in the plasma in Figs. 5 and 6. A similar glasslike microstructure seen for HiPIMS films has been reported from studies conducted on several binary ceramic thin film systems such as $\mathrm{CrN},{ }^{25} \mathrm{TiC},{ }^{26}$ and $\mathrm{ZrB}_{2} \cdot{ }^{27}$ Moreover, the SAED patterns present as insets in Fig. 4 display broken rings of elongated spots, which support the pole figure measurements with a 111 textured growth for both type of films at the highest hydrogen content in the plasma. It was also possible to determine the thicknesses of the deposited films to $\sim 520 \mathrm{~nm}$ for the film grown by HiPIMS, while the film deposited with DCMS is slightly thicker: $\sim 840 \mathrm{~nm}$.

The microstructural evolution is evident from the SEM cross-section images in Fig. 5 for films deposited by HiPIMS and in Fig. 6 for films grown by DCMS. Both reference films in Fig. 5a and Fig. 6a exhibit a ductile plastic behavior typical for metals and with visible surface roughness. Adding hydrogen to the plasma results in a columnar microstructure 
already at $2.5 \% \mathrm{H}_{2}$ in plasma for the HiPIMS films, whereas DCMS films grown under the same condition display more metallic-like properties. This difference in microstructure is supported from the XRD patterns in Fig. 2 showing clear Zr peaks for the DCMS film, while the intensities of these peaks are low compared to the $\delta-\mathrm{ZrH}_{2} 111$ peak in the HiPIMS film. As the hydrogen content is further increased to $10 \%$ and finally $20 \%$, a columnar growth behavior becomes apparent for the DCMS films, while the HiPIMS films now display a more glasslike microstructure and with a smooth surface finish. This is consistent with the TEM micrographs in Fig. 4, and agrees with reports from literature on ceramic HiPIMS films. ${ }^{25-27}$ Furthermore, the difference in microstructure between the metallic reference films and the $\delta$ $\mathrm{ZrH}_{2}$ deposited by HiPIMS and DCMS provides further support for the ceramic-like properties of $\delta-\mathrm{ZrH}_{2}$ films as inducted by the formation of $\mathrm{Zr}-\mathrm{H}$ bonds. The consequences of this interaction on foremost the mechanical properties is presented in section D. The thicknesses for films grown with the highest hydrogen content in the plasma provided by the SEM cross-section images are in good agreement with those obtained by TEM. Images obtained from films deposited at other conditions show typical thicknesses in the range $\sim 750$ $850 \mathrm{~nm}$ and with no clear trends, but the HiPIMS films are generally slightly thinner in particular the reference film $\sim 660 \mathrm{~nm}$ and the film grown with $20 \% \mathrm{H}_{2}$ in the plasma with $\sim 530 \mathrm{~nm}$.

\section{Mechanical properties}

Fig. 7a shows that phase pure $\delta-\mathrm{ZrH}_{2}$ films deposited by both techniques exhibit typical hardness values of 5.5-7 GPa, which is slightly harder than the $\sim 5 \mathrm{GPa}$ determined for $\mathrm{Zr}$ reference films of similar thicknesses. These results are in agreement with the study in (Ref. 9 ), but our hardness values are somewhat higher than the $\sim 4.5 \mathrm{GPa}$ measured for annealed $\delta$ $\mathrm{ZrH}_{2-\mathrm{x}}$ bulk samples and for zirconium metal $\sim 3 \mathrm{GPa} .{ }^{13}$ A possible explanation for the higher 
hardness is the residual compressive stress present in the films, which should also be most pronounced in the HiPIMS films due to the intense ion bombardment. ${ }^{24}$ Our results suggest that the hardness scales with the hydrogen content in the film and that the $\delta-\mathrm{ZrH}_{2}$ films deposited with HiPIMS are slightly harder than those deposited by DCMS, thus reflecting the amount stress depending on the choice of sputtering technique. The influence of the hydrogen content in the films indicates that the interaction between zirconium and hydrogen leads to higher hardness, i.e. more ceramic-like properties. Furthermore, the results from the hardness measurements show that the $\delta-\mathrm{ZrH}_{2}$ films are considerably softer than $\mathrm{ZrC}$ with a hardness value of $25.9 \mathrm{GPa}^{28}$ and $\mathrm{ZrN}$ a reported value of $15.8 \mathrm{GPa}^{28}$ This reflects the difference in degree of directional bonding between hydrides on one side and carbides and nitrides on the other side. The friction measurements revealed scattered $\mu$ values in the range $0.12-0.18$, which are considerably lower than the 0.4 to 0.6 measured for $\mathrm{Zr}$ reference films. This is probably explained by the differences in surface roughness between the metal and the $\delta-\mathrm{ZrH}_{2}$ films, as shown in Figs. 5 and 6. Measurements of the RMS roughness of the films support this suggestion in particular for the films deposited by HiPIMS. For such films the roughness is lowered from $5 \mathrm{~nm}$ to $1.3 \mathrm{~nm}$ and finally to $0.8 \mathrm{~nm}$ for the investigated films grown with $2.5 \%, 10 \%$, and $20 \%$ hydrogen in the plasma, respectively. The films deposited with DCMS follow a similar trend seen from a measured value of $4.9 \mathrm{~nm}$ for the film grown with $2.5 \%$ hydrogen in the plasma and $1.9 \mathrm{~nm}$ for the film grown with $20 \%$ hydrogen in the plasma, but with an increased film roughness to $15.8 \mathrm{~nm}$ for the film grown with $10 \%$ hydrogen in the plasma. The reason for this growth behavior is unclear, but finds support from the SEM image in Fig. 6c. For the wear resistance, there is a clear trend particularly for the HiPIMS films, see Fig. $7 \mathrm{~b}$. As can be seen, the wear rate of the films is lowered when deposited at increasing hydrogen content plasma. For instance, the $\delta-\mathrm{ZrH}_{2}$ films grown with $20 \% \mathrm{H}_{2}$ in the plasma show a wear rate that is $\sim 50$ times lower compared to the films deposited with $2.5 \% \mathrm{H}_{2}$ in the 
plasma; please note the logarithmic scale in Fig. 7b. The wear resistance of films deposited by DCMS is also higher when increasing the hydrogen content in the plasma, albeit lower than their HIPIMS counterpart. Again, we note the difference in surface roughness seen in the SEM pictures in Figs. 5 and 6 as well as the measured film roughness values.

\section{E. Resistivity}

Results from the four-point probe measurements in Table 2 show that all deposited films are good conductors. For the DCMS films, the results indicate increasing resistivity values for films deposited with increasing hydrogen content in the plasma going from $62 \mu \Omega \mathrm{cm}$ to $116 \mu \Omega \mathrm{cm}$ and with the reference film showing a resistivity of $68 \mu \Omega \mathrm{cm}$. For HiPIMS films, the resistivity values are slightly higher compared to the DCMS film deposited at the same process conditions with measured values of $60 \mu \Omega \mathrm{cm}$ to $111 \mu \Omega \mathrm{cm}$ and with the exception of the reference film and a film deposited at the most hydrogen-rich composition. The reason for the higher values obtained for the HiPIMS are likely due to a higher defect density in these films compared to their DCMS counterparts as explained the more intense ion bombardment in HiPIMS. ${ }^{24}$ The values obtained for the films are higher than those reported both for of bulk $\delta-\mathrm{ZrH}_{2}$ and $\varepsilon-\mathrm{ZrH}_{2} \sim 20-80 \mu \Omega \mathrm{cm}$, an observation commonly reported when comparing the thin film with its bulk counterpart, and with the lowest values obtained for the phase $\varepsilon-\mathrm{ZrH}_{2}$ as well as metallic $\mathrm{Zr}$ with a resistivity of $42.6 \mu \Omega \mathrm{cm} .{ }^{11}$ The trend with increasing resistivity values for increasing hydrogen content in our $\delta-\mathrm{ZrH}_{2}$ films can likely be explained by more fine-grained microstructure visible in SEM and in particular for the HiPIMS films. The higher amount of intense ion irradiation present during growth of the HiPIMS is known to induce a repeated nucleation growth behavior $^{25}$, resulting in a more fine-grained microstructure. Considering that the resistivity of a thin film is determined by, among other properties, the grain size of the material, the present observations are reasonable. 


\section{CONCLUSIONS}

We demonstrate that $\delta-\mathrm{ZrH}_{2}$ with 111 fiber texture can be synthesized in thin film form on Si(100) substrates, using reactive sputtering by HiPIMS and DCMS at room-temperature. Our films contain up to 61 at.\% of hydrogen when grown with HiPIMS and exhibits less than 0.2 at.\% of $\mathrm{O}$ and with even lower $\mathrm{C}$ and $\mathrm{N}$ content. The $\delta-\mathrm{ZrH}_{2}$ films exhibit a glasslike microstructure when deposited by HiPIMS, while those deposited by DCMS are columnar. Hardness values in the range 5.5-7 GPa are measured for the $\delta-\mathrm{ZrH}_{2}$ films to compare with the $\sim 5 \mathrm{GPa}$ obtained for $\mathrm{Zr}$ films and with $\mu$ values in the range $0.12-0.18$ being considerably lower than the 0.4-0.6 measured for $\mathrm{Zr}$ reference films. The $\delta-\mathrm{ZrH}_{2}$ films are good conductors with resistivity values in the range of $\sim 100-120 \mu \Omega \mathrm{cm}$, where the values are slightly higher compared to $\mathrm{Zr}$ films as well as bulk $\delta-\mathrm{ZrH}_{2-\mathrm{x}}$ and $\varepsilon-\mathrm{ZrH}_{2-\mathrm{x}}$.

\section{ACKNOWLEDGMENTS}

Grzegorz Greczynski is gratefully acknowledged for assistance with the XPS measurements. $\mathrm{HH}$ acknowledges financial support from the Swedish Research Council (VR) through the Contract No. 622-2008-1247. LH, FE, EB, and HH acknowledge the Swedish Government Strategic Research Area in Materials Science on Functional Materials at Linköping University (Faculty Grant SFO-Mat-LiU No. 2009-00971) for financial support. LH and JJ acknowledge the Linköping Linnaeus Initiative LiLi-NFM, supported by the VR grant No. 2008-6572. The authors are grateful for access to the Tandem Laboratory at Uppsala University. 
${ }^{1}$ T.B. Massalski, J.L. Murray, L.H. Bennett, and H. Baker, Binary Alloy Phase Diagrams (American Society for Metals, Metals Park, Ohio, USA, 1986).

${ }^{2}$ E. Zuzek, J.P. Aribiata, A.S. Martin, and F.D. Manchester, Bull. Alloy Phase Diagrams 11, 385 (1990).

${ }^{3}$ International Centre for Diffraction Data, Zirconium Hydride ( $\left.\delta-\mathrm{ZrH}_{2}\right)$, PDF no. 34-0709.

${ }^{4}$ International Centre for Diffraction Data, Zirconium Hydride ( $\left.\varepsilon-\mathrm{ZrH}_{2}\right)$, PDF no. 17-0314.

${ }^{5}$ L. Holliger, A. Legris, and R. Besson, Phys. Rev. B 80, 094111 (2009).

${ }^{6}$ W. Wolf and P. Herzig, J. Phys.: Condens. Matter 12, 4535 (2000).

${ }^{7}$ R. Quijano, R.de Coss, and D.J. Singh, Phys. Rev. B 80, 184103 (2009).

${ }^{8}$ P. Zhang, B.-T. Wang, C.-H. He, and P. Zhang, Comp. Mater. Sci. 50, 3297 (2011).

${ }^{9}$ T. Chihi, M. Fatmi, and A. Bouhemadou, Solid State Sciences 14, 583 (2012).

${ }^{10}$ J.D. Corbett and H.S. Marek, Inorg. Chem. 22, 3194 (1983).

${ }^{11}$ P.W. Bickel and T.G. Berlincourt, Phys. Rev. B 2, 4807 (1970).

${ }^{12}$ S. Yamanaka, K. Yamada, K. Kurosaki, M. Uno, K. Takeda, H. Anada, T. Matsuda, and S. Kabayashi, J. Alloys Comp. 330-332, 99 (2002).

${ }^{13}$ K Kuroda, D. Setoyama, M. Uno, and S. Yamanaka, J. Alloys Comp. 368, 211 (2004).

${ }^{14}$ M. Ito, D. Setoyama, J. Matsunaga, H. Muta, K. Yamada, K. Kurosaki, M. Uno, and S. Yamanaka, J. Alloys Comp. 426, 67 (2006).

${ }^{15}$ J.L. Vossen and W. Kern, Thin Film Processes (Academic Press, Inc., New York, 1978). 
${ }^{16}$ O. Knotek, M. Böhmer, and T. Leyendecker, J. Vac. Sci. Technol. A 4, 2695 (1986).

${ }^{17}$ S. Hüfner, Photoelectron Spectroscopy: Principles and Applications, 3rd ed. (SpringerVerlag, 2010).

${ }^{18}$ H.J. Whitlow, G. Possnert, and C.S. Petersson, Nucl. Instrum. Methods Phys. Res. Sect. B: Beam Interact. Mater. At. 27, 448 (1987).

${ }^{19}$ J. Jensen, D. Martin, A. Surpi, and T. Kubart, Nucl. Instrum. Methods Phys. Res. Sect. B: Beam Interact. Mater. At. 268, 1893 (2010).

${ }^{20}$ P. Zhang, L. Wang, and X. Nie, Surf. Coat. Technol. 201, 5176 (2007).

${ }^{21}$ A.L. Allred, J. Inorg. Nucl. Mater. 17, 215 (1961).

${ }^{22}$ H. Högberg, L. Tengdelius, M. Samuelsson, J. Jensen, and L. Hultman, Physica B 439, 3 (2014).

${ }^{23}$ R. Nyholm and N. Mårtensson, J. Phys. C: Solid St. Phys. 13, L279 (1980).

${ }^{24}$ K. Sarakinos, J. Alami, and S. Konstantinidis, Surf. Coat. Technol. 204, 1661 (2010).

${ }^{25}$ A.P Ehiasarian, P.Eh Hovsepian, L Hultman, and U Helmersson, Thin Solid Films 457, 270 (2004).

${ }^{26}$ M. Samuelsson, K. Sarakinos, H. Högberg, E. Lewin, U. Jansson, B. Wälivaara, H.Ljungcrantz, and U. Helmersson, Surf. Coat. Technol. 206, 2396 (2012).

${ }^{27}$ M. Samuelsson, J. Jensen, U. Helmersson, L. Hultman, and H. Högberg, Thin Solid Films 526, 163 (2012). 
${ }^{28}$ H.O. Pierson, Handbook of Refractory Metal Carbides and Nitrides (Noyes, New Jersey, 1996). 
Table I. Compositions and level of contaminants for Zr-H films deposited by HiPIMS and DCMS determined from ToF-E ERDA measurements. The marking * and ** represent two separate measurements on one HiPIMS and one DCMS films following five months of storage in air.

\begin{tabular}{|c|c|c|c|c|c|c|}
\hline $\begin{array}{l}\text { Deposition } \\
\text { technique }\end{array}$ & $\begin{array}{c}\mathrm{H}_{2} \\
\text { content in } \\
\text { plasma } \\
(\%)\end{array}$ & $\begin{array}{c}\mathrm{H}] \\
\text { at. } \%\end{array}$ & $\begin{array}{l}\mathrm{Zr}] \\
\text { at. } \%\end{array}$ & $\begin{array}{c}\text { [O] } \\
\text { at. } \%\end{array}$ & $\begin{array}{c}\text { [C] } \\
\text { at. } \%\end{array}$ & $\begin{array}{c}{[\mathrm{Ar}]+[\mathrm{N}]} \\
\text { at. } \%\end{array}$ \\
\hline \multirow[t]{5}{*}{ HiPIMS } & $\overline{5}$ & 55 & 45 & $<0.1$ & $<0.1$ & 0 \\
\hline & 10 & 59.1 & 40.4 & 0.2 & 0 & $0.2 \mathrm{Ar}$ \\
\hline & 15 & 58.6 & 40.8 & 0.2 & 0.1 & $0.3 \mathrm{Ar}$ \\
\hline & $20^{*}$ & 61.1 & 38.6 & 0.1 & 0 & $0.2 \mathrm{Ar}$ \\
\hline & $20^{* *}$ & 59.6 & 39.7 & 0.2 & 0.1 & 0.4 \\
\hline \multirow[t]{3}{*}{ DCMS } & 10 & 22.9 & 76.3 & 0.7 & 0.1 & 0 \\
\hline & $20^{*}$ & 53.6 & 46.1 & 0.2 & 0.1 & 0 \\
\hline & $20^{* *}$ & 50.5 & 49 & 0.3 & 0.1 & $0.1 \mathrm{Ar}$ \\
\hline
\end{tabular}

Table II. Four-point probe resistivity values for $\mathrm{Zr}$ reference films and $\mathrm{Zr}-\mathrm{H}$ films deposited by HiPIMS and DCMS, using different hydrogen content in the plasma.

\begin{tabular}{|c|c|c|}
\hline \multirow{2}{*}{$\mathrm{H}_{2}$ content in the plasma } & \multicolumn{2}{|c|}{ Resistivity $(\mu \Omega \mathrm{cm})$} \\
\cline { 2 - 3 }$(\%)$ & HiPIMS & DCMS \\
\hline 0 & 60 & 68 \\
\hline 2.5 & 93 & 62 \\
\hline 5 & 108 & 69 \\
\hline 10 & 88 & 87 \\
\hline 15 & 101 & 96 \\
\hline 20 & 111 & 116 \\
\hline
\end{tabular}




\section{Figure Captions}

Figure 1. High-resolution XPS Zr 3d spectra from a $\delta-\mathrm{ZrH}_{2}$ film deposited by HiPIMS with $20 \% \mathrm{H}_{2}$ in the plasma (solid line) and a $\mathrm{Zr}$ reference film grown by HiPIMS (dashed line). The vertical dashed lines represent the peak positions determined for $\mathrm{Zr} 3 \mathrm{~d}_{5 / 2}$ and $\mathrm{Zr} 3 \mathrm{~d}_{3 / 2}$ in bulk zirconium (Ref. 23).

Figure 2. X-ray $\theta / 2 \theta$ scans from films deposited by HiPIMS to the left and DCMS to the right and using from the bottom of the stack: $0 \%, 2.5 \%, 5 \%, 10 \%, 15 \%$, and $20 \%$ of $\mathrm{H}_{2}$ in the plasma. The inset is a diffractogram recorded from a film deposited by DCMS and using $20 \% \mathrm{H}_{2}$ in the plasma, where the needle shaped peaks at $2 \theta \approx 17^{\circ}$ and $2 \theta \approx 27^{\circ}$ are detector artefacts.

Figure 3. X-ray pole figures for a $\delta$ - $\mathrm{ZrH}_{2}$ film deposited by HiPIMS with $15 \% \mathrm{H}_{2}$ in the plasma showing: in a) the 220 pole and in b) the 420 pole.

Figure 4. TEM micrographs with SAED pattern as insets in (a) from a $\delta-\mathrm{ZrH}_{2}$ film deposited by HiPIMS and (b) from a $\delta-\mathrm{ZrH}_{2}$ film deposited by DCMS and using $20 \% \mathrm{H}_{2}$ in the plasma during growth of both films.

Figure 5. SEM images obtained from films deposited by HiPIMS: in (a) a 660 $\mathrm{nm}$ thick $\mathrm{Zr}$ reference film, in (b) a $\sim 780 \mathrm{~nm}$ thick film deposited with $2.5 \% \mathrm{H}_{2}$ in the plasma, in (c) a 780 nm thick deposited with $10 \% \mathrm{H}_{2}$ in the plasma, and in (d) a 530 nm thick film deposited with $20 \% \mathrm{H}_{2}$ in the plasma.

Figure 6. SEM images obtained from films deposited by DCMS: in (a) a 800 nm thick $\mathrm{Zr}$ reference film, in (b) a $\sim 750 \mathrm{~nm}$ thick film deposited with $2.5 \% \mathrm{H}_{2}$ in the plasma, in (c) a $\sim 850 \mathrm{~nm}$ thick deposited with $10 \% \mathrm{H}_{2}$ in the plasma, and in (d) a $\sim 860 \mathrm{~nm}$ thick film deposited with $20 \% \mathrm{H}_{2}$ in the plasma. 
Figure 7. Hardness values determined from nanoindentation of films deposited with DCMS and HiPIMS in hydrogen containing plasmas in (a) and wear resistance for films deposited with DCMS and HiPIMS in hydrogen containing plasmas in (b). Note the logarithmic scale for the wear rate used in (b). 
Figure 1.

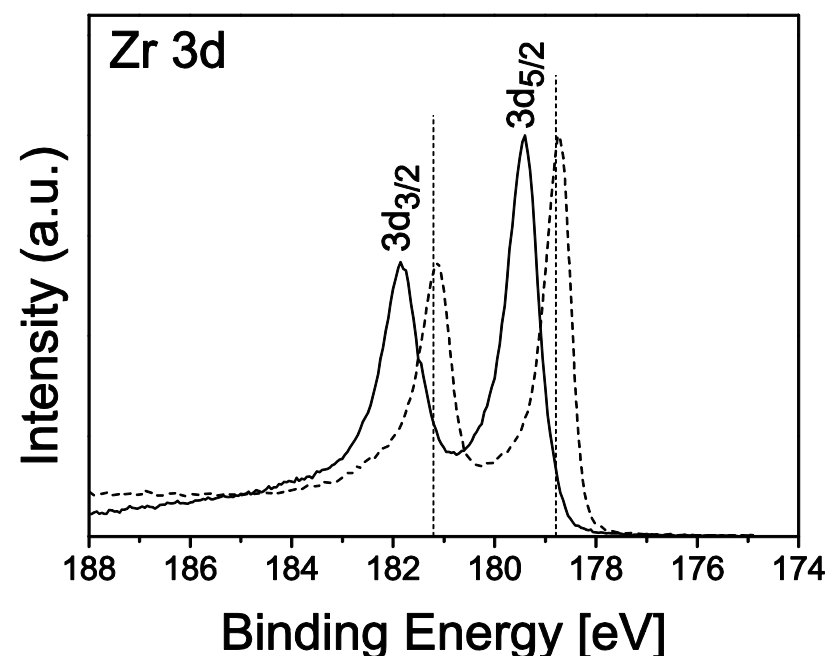


Figure 2.

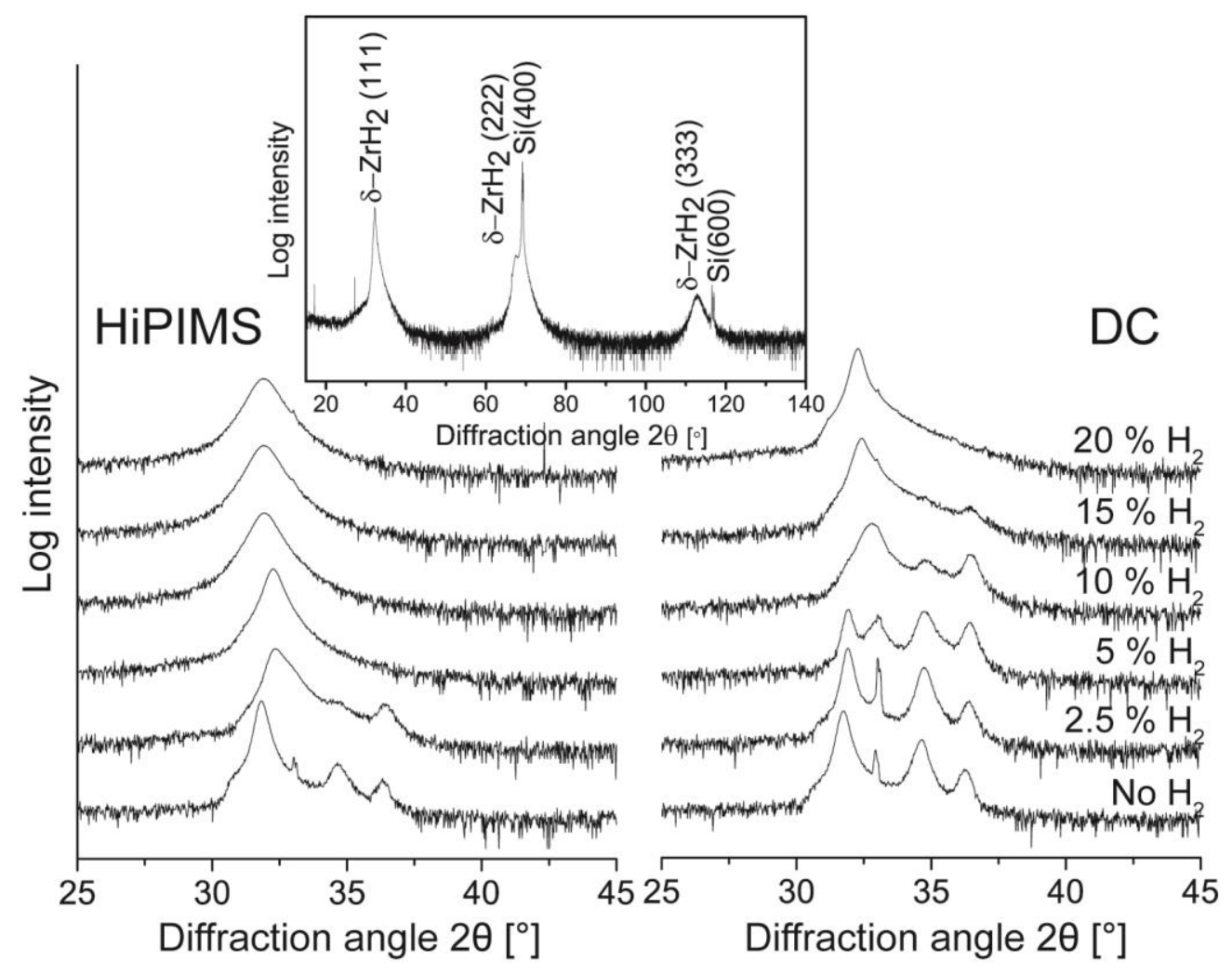


Figure 3.

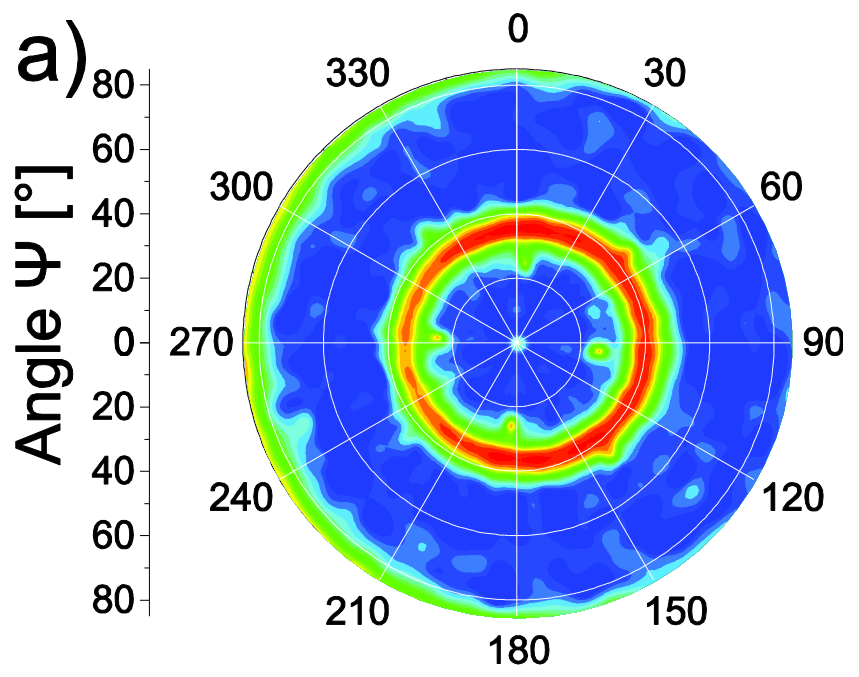

Angle $\varphi\left[{ }^{\circ}\right]$

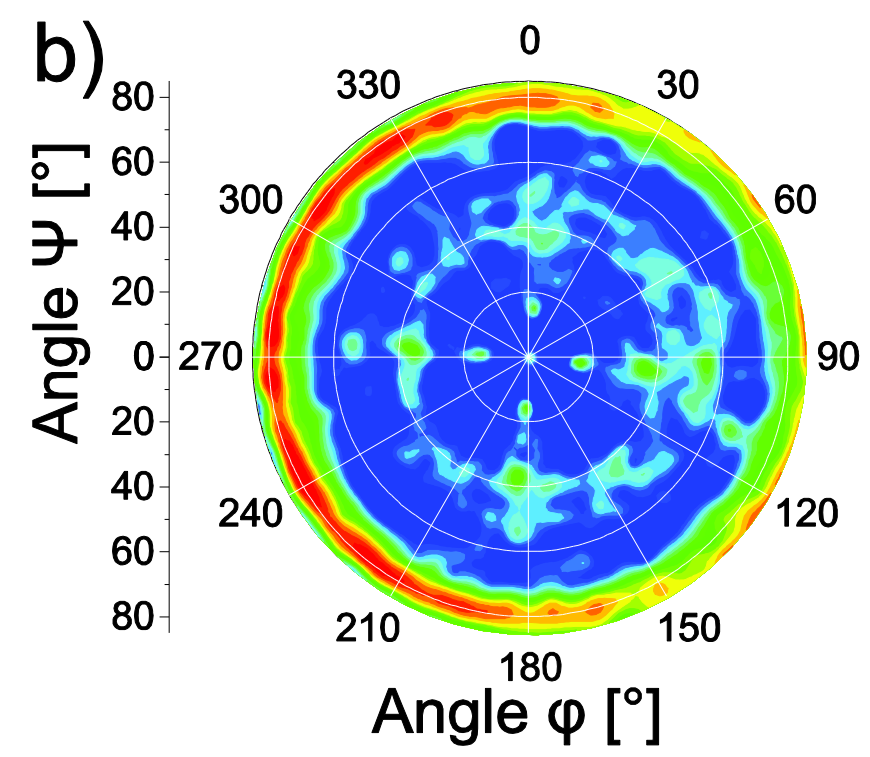


Figure 4.

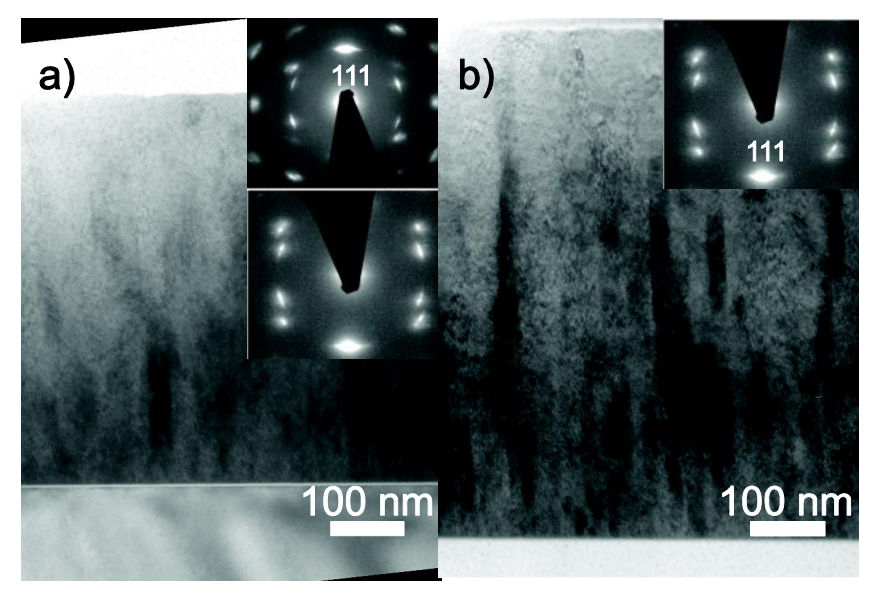


Figure 5.

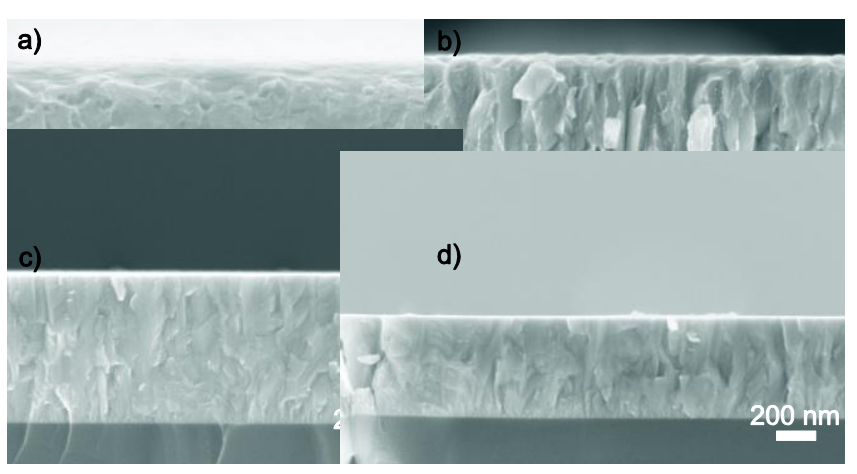


Figure 6.

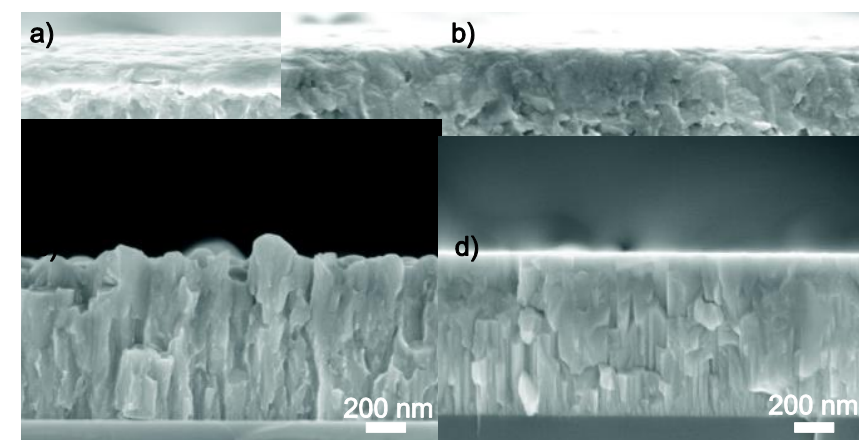


Figure 7.
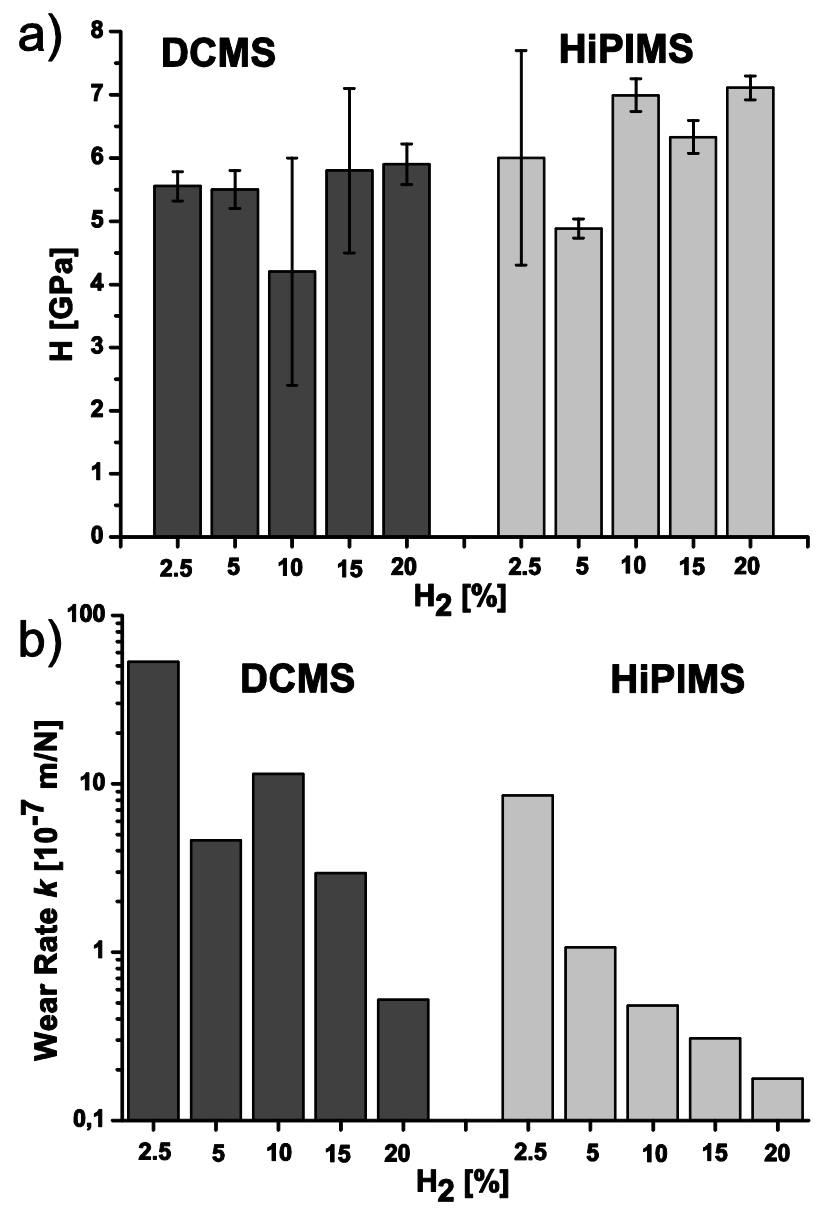